\title{
Knowledge Regarding Modifiable Risk Factors of Coronary Atherosclerosis Heart Diseases in Kathmandu Municipality
}

\author{
Khadka M
}

\begin{abstract}
Background

Progressive urbanization and adoption of the "western" lifestyle contributes to the rising burden of cardiovascular disease in the developing world Coronary Atherosclerotic Heart Disease is no longer confined by geographical area or socioeconomic boundary. The prevalence of Coronary Atherosclerotic Heart Disease is increasing in Nepal. Knowledge is an important pre-requisite for implementing both primary and secondary preventive strategies for cardiovascular diseases. This investigation attempts to quantify knowledge of modifiable risk factors of Coronary Atherosclerotic Heart Disease among sample population in Kathmandu metropolitan city.
\end{abstract}

\section{Methods}

Community based cross-sectional descriptive study design using quantitative method of study was conducted in ward no 5 of Kathmandu out of 35 wards. Selection was done by simple random technique (lottery method). Total house hold serial number of selected ward was identified from election commission record section and data was collected using systemic random sampling. The household head aged 18 years and above was taken as representative sample $(n=196)$. Standard questionnaire was used to interview participants. The risk factors specifically included smoking, hypertension, elevated cholesterol levels, diabetes mellitus and obesity.

Results

The mean age (SD) of the 196 participants was 51.26 (13.56) years. Of the participants only $22 \%$ had good level of knowledge regarding modifiable risk factors of Coronary Atherosclerotic Heart Disease. This study showed that majority of the respondent lack predefined good level of knowledge regarding modifiable risk factors of Coronary Atherosclerotic Heart Disease. 85.2\%, 61.73\%, 40.31\%, 28.6\%, $17.86 \%$ correctly identified hypertension, obesity, cholesterol, smoking and diabetes mellitus respectively as modifiable risk factor of Coronary Atherosclerotic Heart Disease. Stud y found association of good level of knowledge in male participants ( $p=0.006)$, Brahmin cast $(p=0.001)$, living in nuclear family $(p=0.041)$, ex-smoker $(p=0.06)$, doing regular exercise $(p=0.006)$.

\section{Conclusion}

This study call for efforts such as targeted public health education to increase the level of knowledge about the modifiable risk factors of heart disease.

Key words Knowledge, coronary atherosclerosis heart diseases, cross-sectional study, Nepal 


\section{Introduction}

CASHD is the leading cause of death in the world. It accounts for nearly $30 \%$ of death globally; even in low income and lower middle income countries CASHD results in $27 \%$ of total death. Further tuberculosis, malaria and AIDS result in only $10 \%$ of death globally. ${ }^{1}$

The WHO has drawn attention to the fact that CASHD modern epidemic of developing countries. Myocardial infarction is a leading cause of death in industrial nations. Even in a developing country like Nepal, it is emerging as a major public health problem. Although CASHD declined in developed countries from 1980 to 2000, the World Health Organization predicts that CASHD will become the major cause of death in almost all countries by 2020, with over 10 million deaths per year predicted. Progressive urbanization and adoption of a "western" lifestyle contributed to the rising burden of cardiovascular disease in the developing countries. $^{2,3}$

Developing countries are repeating the earlier lifestyle mistakes of developed countries. Economists predict that rising CASHD costs will greatly sap these countries' resources, delay economic growth, and cause unnecessary suffering. ${ }^{4}$ South Asia comprises $25 \%$ of the global population yet contributes nearly $60 \%$ of the global cardiovascular disease burden. Smoking, hypertension, and diabetes are strongly associated with CASHD among south Asian. ${ }^{5,6}$

Prevention of CASHD is the most effective way of combating the CASHD epidemic in the resource poor nations. Knowledge of the predisposing risk factors is important. One method of targeting preventive educational strategies involves measuring and appropriately disseminating knowledge of the modifiable risk factors. Earlier studies have revealed that education programs for the elderly were effective in improving health promotion knowledge and behaviors. ${ }^{7,8}$ Although knowledge alone is insufficient, it is assumed to be a key component of behavioral change decision making, ${ }^{9}$ and provides cues for action. ${ }^{10}$ Estimating the level of knowledge of the population at large as well as those suffering from CVD can help to guide public health programs especially those directed towards reducing modifiable risk factors for CASHD.

The level of knowledge of risk factors for CASHD varies among different populations. In investigations in the western world, such as in Canada ${ }^{11}$ shows that individuals at greater risk of cardiovascular disease are elderly and those with low education levels and are least able to recall risk factors associated with CASHD.

Similarly, in the UK, South Asian families were less likely to take regular exercise, and had a lower awareness of cholesterol or dietary content (fiber, sugar, salt) compared to the native white population. ${ }^{12,13}$ A similar study in Saudi Arabia shows that physically inactive people were least aware of their risk of CASHD. ${ }^{14}$ A lack of cardiovascular health knowledge in the general population in Pakistan that reports limited knowledge of modifiable risk factors of heart disease in patients who had experienced an acute myocardial infarction. ${ }^{15,16}$ This Pakistani study isolated specific demographic factors that correlate with lower knowledge of CASHD risk factors, such as fewer than ten years of formal education, current usage of tobacco, and a nuclear family. A study done in neighboring India has also identified the poor knowledge among a sampled Indian population regarding modifiable risk factors of CASHD, especially DM and study notably reveals certain characteristics that are significant predictors of poor knowledge levels of modifiable risk factors. Participants who reported low levels of routine exercise and who are current smokers had a significant poor knowledge level. ${ }^{17}$

This study evaluated the knowledge levels of the modifiable risk factors among sample of Katmandu metropolitan city. The risk factors included smoking, hypertension, elevated cholesterol levels, DM, and obesity. This study also identified gaps in the knowledge of specific risk factors as well as key demographic segments with significantly poor levels of knowledge pertaining to modifiable risk factors of CASHD.

\section{Methods}

Community based Cross-Sectional descriptive study design using quantitative method, study was conducted in Kathmandu municipality which consists of 35 wards out of which one ward which was selected by simple random technique lottery method i.e. ward no 5. Confidence interval 95\%, allowable error $10 \%$ and people having knowledge about modifiable risk factor of coronary artery diseases is estimated to be $50 \%$.

Sample size is calculated by applying following formula:

$$
n=4 p q / L^{2}
$$

Where, $\quad n=$ number of sample size

$$
\begin{aligned}
& P=50 \% \\
& q=1-50=50 \% \\
& L=\text { allowable error }(10 \%)
\end{aligned}
$$

Sample Size $(n)=177$

The minimum sample size for the study comes to be 196

Estimated non-response rate $10 \%$

The final sample size is 196 
Sampling was done in two phase:

$1^{\text {st }}$ phase: From 35 wards of Kathmandu 1 ward was selected randomly by lottery method.

$2^{\text {nd }}$ phase: Total house hold serial number of selected ward was identified from election commission record section and data was collected using systemic random sampling i.e. every interval of $34^{\text {th }}$ house was taken and the household head aged 18 years and above were taken for the study Structured questionnaire for face to face interview was developed. Participants were interviewed by providing with structured questionnaire under supervision to prevent from multiple respondents. Before taking the interview participants were instructed to say "yes" for risk factor that they felt definitely contribute to CASHD otherwise say "not sure".

Out of ten risk factor included in survey, five are clearly known to cause CASHD and additional non-associated risk factors were included in the questionnaire to maintain validity of responses and avoid false positives that could be generated by random responses. After finishing the interview session the correct answers were explained to the participants. This survey questionnaire is taken from similar study done in India.

Correctly identifying four or more risk factor was regarded as good level of knowledge, while identifying three or less risk factors was regarded as poor level of knowledge and this scaling of knowledge is done based on the similar study done in India to assess knowledge of modifiable risk factor of CASHD. ${ }^{19}$

\section{Results}

The mean age (SD) was $51.26(13.56)$ years of the total participants 196 . Of the total $67.35 \%$ were male. Of the participants $78.5 \%$ literate, $0.51 \%$ had family history of heart attack, $1.02 \%$ were known case of diabetes mellitus, $2.04 \%$ were know case of $\mathrm{HTN}, 0.51 \%$ were known case of myocardial infarction. The results indicate that the majority $(77.55 \%)$ of individuals sampled lacked adequate awareness of modifiable risk factors of CASHD. The present study also demonstrates that $27.55 \%$ of participants were able to recognize at least two risk factors for heart disease, but only $8.16 \%$ of the participants were fully aware of all five key modifiable risk factors of heart disease. This study shows that majority of the respondent lack predefined good level of knowledge regarding modifiable risk factors of CASHD $85.2 \%, 61.73 \%, 40.31 \%, 28.6 \%, 17.86 \%$ correctly identified hypertension, obesity, cholesterol, smoking and diabetes mellitus as modifiable risk factor of CASHD.

Table 2 shows the association between knowledge level and selected variables. Table shows that male respondent do have statistically significant higher level of knowledge than female $(p=0.006)$. Brahmin had higher level of knowledge than any other ethnic group $(p=0.001)$. Though statistically insignificant literate group had better knowledge about modifiable risk factors than illiterate group. Those participants living in nuclear family had good level of knowledge which is statistically significant (0.041). Those who had quit smoking had good level of knowledge regarding modifiable risk factors of CASHD( 0.06). Those who are regular in exercise had statistically significant good level of knowledge ( 0.006)

Table1: Demographic characteristics of participants $(n=196)$

\begin{tabular}{|c|c|c|}
\hline Characteristics & $\mathrm{n}$ & $\%$ \\
\hline \multicolumn{3}{|l|}{ Age } \\
\hline below 35 years & 24 & 12.24 \\
\hline above 35 years & 172 & 87.76 \\
\hline \multicolumn{3}{|l|}{ Sex } \\
\hline male & 132 & 67.35 \\
\hline Female & 64 & 32.65 \\
\hline \multicolumn{3}{|l|}{ Religion } \\
\hline Hindu & 168 & 85.71 \\
\hline Buddhist & 24 & 12.24 \\
\hline Christian & 3 & 1.53 \\
\hline Muslim & 1 & 0.51 \\
\hline \multicolumn{3}{|l|}{ Ethnic group } \\
\hline Brahmin & 35 & 17.86 \\
\hline Chetri & 60 & 30.61 \\
\hline Newar & 83 & 42.35 \\
\hline Others & 18 & 9.18 \\
\hline \multicolumn{3}{|l|}{ Marital status } \\
\hline Married & 190 & 96.94 \\
\hline Unmarried & 4 & 2.04 \\
\hline Divorced & 2 & 1.02 \\
\hline \multicolumn{3}{|l|}{ Education } \\
\hline Illiterate & 42 & 21.42 \\
\hline Literate & 154 & 78.58 \\
\hline \multicolumn{3}{|l|}{ Family } \\
\hline Nuclear & 85 & 43.37 \\
\hline Extended & 111 & 56.63 \\
\hline \multicolumn{3}{|l|}{ Occupation } \\
\hline Service & 64 & 32.65 \\
\hline Business & 62 & 31.63 \\
\hline Unemployed & 32 & 16.33 \\
\hline Retired & 38 & 19.39 \\
\hline \multicolumn{3}{|l|}{ Smoking habit } \\
\hline Never used & 69 & 35.2 \\
\hline Current user & 106 & 54.08 \\
\hline
\end{tabular}




\section{Nepalese Heart Journal}

\begin{tabular}{lll}
\hline ex-user & 21 & 10.71 \\
\hline Exercise & & \\
\hline Non or infrequent & 162 & 82.65 \\
Regular* & 34 & 17.35 \\
\hline Family history of heart attack & & \\
\hline Yes & 1 & 0.51 \\
No & 195 & 99.49 \\
\hline Known case of DM & & \\
\hline Yes & 2 & 1.02 \\
No & 194 & 98.98 \\
\hline Known case of HTN & & \\
\hline Yes & 4 & 2.04 \\
\hline No & 192 & 97.96 \\
\hline Known case of MI & & 9.51 \\
\hline Yes & 1 & 99.49 \\
\hline No & 195 & \\
\hline
\end{tabular}

* at least 3 times a week and greater than 30 minutes during each session.

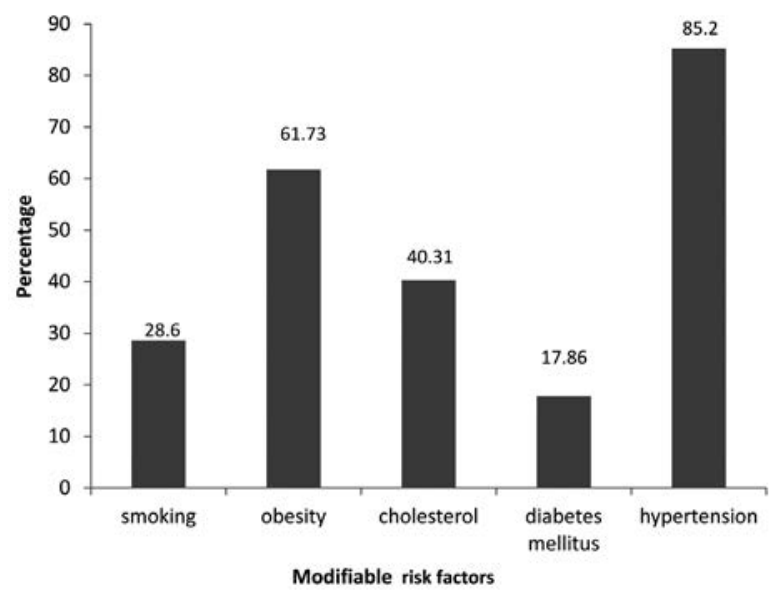

Fig 1: Knowledge of particular risk factors of CASHD $(n=196)$

Table 2: Association between "good" level of knowledge of modifiable risk factors with specific demographic variables ( $\mathrm{n}=196)$

\begin{tabular}{|c|c|c|c|c|c|c|}
\hline \multirow[b]{2}{*}{ Variables } & \multicolumn{2}{|c|}{ Knowledge level $n$ (\%) } & \multirow[b]{2}{*}{ Odds ratio } & \multicolumn{2}{|c|}{ 95\% confidence interval } & \multirow[b]{2}{*}{$P$ value } \\
\hline & Good knowledge* & Poor knowledge** & & Lower & Upper & \\
\hline \multicolumn{7}{|l|}{ Sex } \\
\hline Male & 37 & 95 & 3.171 & 1.326 & 7.585 & 0.006 \\
\hline Female & 7 & 57 & 1 & & & \\
\hline \multicolumn{7}{|l|}{ Age } \\
\hline below 35years & 6 & 18 & 1.175 & 0.436 & 3.169 & 0.749 \\
\hline above 35 years & 38 & 134 & 1 & & & \\
\hline \multicolumn{7}{|l|}{ Ethnic group } \\
\hline Brahmin & 16 & 19 & 4 & 1.834 & 8.726 & 0.001 \\
\hline others & 28 & 133 & 1 & & & \\
\hline \multicolumn{7}{|l|}{ Education } \\
\hline illiterate & 2 & 40 & 0.113 & 0.031 & 0.576 & 0.002 \\
\hline literate & 42 & 112 & 1 & & & \\
\hline \multicolumn{7}{|l|}{ Family } \\
\hline Nuclear & 25 & 60 & 2.018 & 1.023 & 3.98 & 0.041 \\
\hline Extended & 19 & 92 & 1 & & & \\
\hline \multicolumn{7}{|l|}{ Smoking habit } \\
\hline current user & 22 & 84 & 1.31 & 0.57 & 3.06 & 0.49 \\
\hline Excuser & 10 & 11 & 4.55 & 1.4 & 14.99 & 0.06 \\
\hline Never smoked & 12 & 60 & 1 & & & \\
\hline \multicolumn{7}{|l|}{ Exercise } \\
\hline Regular & 14 & 20 & 3.08 & 1.398 & 6.784 & 0.006 \\
\hline non or infrequent & 30 & 132 & 1 & & & \\
\hline
\end{tabular}

* Correctly identifying four or more risk factors.

** identifying three or less risk factors 


\section{Discussion}

The study indicates that the majority (77.55\%) of individuals sampled lacked adequate awareness of modifiable risk factors of CASHD. The present study also demonstrates that $27.55 \%$ of participants were able to recognize at least two risk factors for heart disease, but only $8.16 \%$ of the participants were fully aware of all five key modifiable risk factors of heart disease. The level of knowledge of participants is considerably lower which is consistent with study done in Pakistan and India. ${ }^{16,17}$

One particular area of interest is knowledge of cigarette smoking as a modifiable risk factor for CASHD. Importantly, only $28.6 \%$ of participants correctly identified smoking cigarettes as a modifiable risk factor of CASHD. It is an important and reversible risk factor for CASHD. Incidence of myocardial infarction is increased six fold in women and three fold in men who smoke at least 20 cigarettes per day compared to subjects who never smoked. ${ }^{18}$ This result is consistent with study conducted in four tertiary hospital of Pakistan where only31.9\% could identify smoking as risk factor. ${ }^{16}$ This similar lack of knowledge is found in other south Asians. ${ }^{19}$ This finding is especially worrisome that significant number of people fails to identify smoking as risk factor of heart diseases as Nepal has amongst the highest percentage of smokers. In Nepal $49 \%$ men and $29 \%$ women smoke the highest in the world. ${ }^{20}$ It is possible that the very poor awareness about smoking is related to their under representation in mass media campaigns as opposed to smoking and suggests the need for urgent emphasis on education amongst Nepalese. Nepal lacks the infrastructure of educational facilities and programs vital to raising awareness and knowledge of smoking and its contribution to atherosclerotic cardiovascular disease and needs educating the people through mass media and introducing the strong law against smoking at public places.

A significant percentage (82.14\%) of participants failed to identify DM as a risk factor. This result is consistent with studies conducted among urban adult Indians that found a low level of awareness of DM. ${ }^{17,21}$

Study shows that there is association between level of knowledge between male and female, male participants have good level of knowledge which is statistically significant $(p=0.006)$.The possible description of it would be our society is male dominant and literacy rate is higher in male and they do have more health seeking behavior than female.

Brahmin subject showed statistically significant good level of knowledge $(p=0.001)$. Earlier studies have shown a clear distinction in various health belief and health seeking behavior among different ethnic group. ${ }^{22}$ This signifies that while conducting health awareness programs other ethnic group need be in more focused.
Those living in nuclear family have significant association of good knowledge $(p=0.041)$. A significant majority of the participants $56.63 \%$ were noted to be living in an extended family system. Interestingly, subjects who lived in extend family system had less knowledge about modifiable risk factors. One would have thought that those living in an extended family would have been more likely to be exposed to close relatives with heart disease and thus to the advices that was offered but the data do not support this There are several possible explanation of this observation. The frequent and close contact of an extended family system may lead to exposure and reinforcement of traditional and potentially unhealthy health practice and beliefs. ${ }^{23}$

In this study smokers were less knowledgeable about risk factors. Ex-smokers had statistically significant good level of knowledge (0.06) This finding is consistent with other studies conducted in the Saudi Arabia, Pakistan and India. ${ }^{14,16,17}$

Very few people are involved in regular exercise habit. Those who are regular in exercise had statistically significant good level of knowledge (0.006), this finding is consistent wirth previous studies. . $^{11,18,19}$

\section{Conclusion}

Study finding highlight a striking lack of knowledge of modifiable risk factors among individuals. The result of study have also helped to identify the segment of population who need to be targeted; those includes tobacco users, illiterate grope, those living in extended family system, other ethnic group that Brahmin. The finding of this study suggests that aggressive and targeted education about the relationship of modifiable risk factors specially smoking and DM and about role of exercise with CASHD.

This study call for efforts such as targeted public health education to increase the level of knowledge about the modifiable risk factors of heart disease. The program must be sensitive to the attitude, perception and capabilities of targeted individuals. Physician must also ensure that they impart education to their clients as the patients usually rely on doctors for first hand information .Further epidemiological longitudinal studies and population based are needed in Nepal to assess the knowledge regarding modifiable behavioral risk factors for heart diseases.

Study despite some limitations, should raise strong concern about the lack of knowledge and awareness about the CASHD and should serve as a stimulus for establishing health education programs. Prevention of CASHD is most effective way of combating its epidemic in the resource poor nation like Nepal as it is said that one ounce of prevention is better than one pound of cure. 


\section{Nepalese Heart Journal}

\section{Acknowledgemnet:}

The author would like to thank Mr. Umesh Raj Aryal (Lecturer of Biostatistics, Department of Community Medicine, Kathmandu Medical College) for his guidance for the data analysis of this study.

\section{References:}

1. AndersonGF, Chu E. Expanding priorities, confronting chronic diseases in countires with low income. N Engl J Med 2007; 356: 209-11.

2. Reddy KS, Yusuf S. Emerging epidemic of cardiovascular disease in developing countries.Circulation1998;97:596-601.

3. World Health Organization. Disease Statistics World Health Report. Mortality by sex, cause and WHO Regions, Estimates for 1998. 1999.

4. Murray CJL, Lopez AD. The Global Burden of Disease: A Comprehensive Assessment of Mortality and Disability from Disease, Injuries, and Risk Factors in 1990 and Projected to 2020. Cambridge, MA: Harvard University Press.

5. Sheth T, Nair C, Nargundkar M, et al. Cardiovascular and cancer mortality among Canadians of European, South Asian and Chinese origin from 1979 to 1993: an analysis of 1.2 million deaths. Can Med Assoc J 1999;161:132-8.

6. Enas EA, Garg A, Davidson MA, et al. Coronary heart disease and its risk factors in first-generation immigrant Asian Indians to the United States of America. Indian Heart J 1996;48:34353.

7. Huang LH, Chen SW, Yu YP, et al. The effectiveness of health promotion education programs for community elderly. J Nurs Res 2002;10(4):261-70.

8. Kirk-Gardner R, Steven D. Hearts for Life: a community program on heart health promotion. Can J Cardiovasc Nurs 2003;13(1):5-10.

9. Ford ES, Jones DH. Cardiovascular health knowledge in the United States: findings from the National Health Interview Survey, 1985. Prev Med 1991;20(6):725-36.

10. Becker MH, Maiman LA, Kirscht JP, et al. The Health Belief Model and prediction of dietary compliance: a field experiment. J Health Soc Behav 1977;18(4):348-66.

11. Potvin L, Richard L, Edwards AC. Knowledge of cardiovascular disease risk factors among the Canadian population: relationships with indicators of socioeconomic status. CMAJ 2000;162(9 Suppl):S5-S11.

12. Lip GY, Luscombe $C$, McCarry M, et al. Ethnic differences in public health awareness, health perceptions and physical exercise: implications for heart disease prevention. Ethn Health 1996;1(1):47-53.

13. Rankin J, Bhopal R. Understanding of heart disease and diabetes in a South Asian community: cross-sectional study testing the 'snowball' sample method. Public Health 2001;115(4):253-60.

14. Khattab MS, Abolfotouh MA, Alakija W, et al. Risk factors of coronary heart disease: attitude and behaviour in family practice in Saudi Arabia. East Mediterr Health J 1999;5(1):3545.

15. Jafary FH, Aslam F, Mahmud $\mathrm{H}$, et al.Cardiovascular health knowledge and behavior in patient attendants at four tertiary care hospitals in Pakistan - a cause for concern. BMC Public Health 2005;5:124.

16. Khan MS, Jafary FH, Jafar TH, et al. Knowledge of modifiable risk factors of heart disease among patients with acute myocardial infarction in Karachi, Pakistan: a cross sectional study. BMC Cardiovasc Disord 2006;6:18.

17. Saeed O, Gupta V, Dhawan N, et al. Knowledge of modifiable risk factors of Coronary Atherosclerotic Heart Disease (CASHD) among a sample in India: BMC International Health and Human Rights 2009;9:2.

18. Npolstadl, Arnesen E, Larsen PG. Smoking, serum lipids ,blood pressure and sex difference in myocardial infarction. Circulation 1996; 93;450.

19. Khattab MS, Abolfotouh MA, Alakija W, et al. Risk factors of coronary heart disease: attitude and behaviour in family practice in Saudi Arabia. East Mediterr Health J 1999;5(1):3545.

20. Pandey MR, Pathak RP, Shrestha S, et al. Global youth tobacco survey; 2007.

21. Murugesan N, Snehalatha C, Shovana R, et al. Awareness about diabetes and its complication in the general and diabetic population in a city in Southern India. Diabetic Res Clin Pract 2007;77:433-7.

22. Farooqi A, Nagra D, Edger T, et al. Attitude to lifestyle risk factor for coronary heart diseases among South Asians in Leicester; a focus group study. Fam pact 2000;17(4):293-7.

23. Shah $Q$, Sonuga- Barke E: Family structure and the mental health of Pakistan Muslims mothers and their children living in Britain. Br J Clin Psychol 1995;34(1):79-81. 